\title{
Short Communication: Effect of Production Variables on the Cis-9, Trans-11 Conjugated Linoleic Acid Content of Cows' Milk*
}

\author{
A. L. Lock, ${ }^{1} †$ D. E. Bauman, ${ }^{2}$ and P. C. Garnsworthy ${ }^{1}$ \\ ${ }^{1}$ Division of Agricultural and Environmental Sciences, University of Nottingham, Loughborough, LE12 5RD, UK \\ ${ }^{2}$ Department of Animal Science, Cornell University, Ithaca, NY 14853
}

\begin{abstract}
Although there have been numerous studies investigating effects of nutrition and individual variation on the concentration of cis-9, trans-11 conjugated linoleic acid (rumenic acid; RA) in milk, there is limited information on relationships among RA content of milk and production variables. The objective of the current analysis was to examine the effects of production variables on RA content and desaturase index of milk fat. A total of 430 samples were collected from cows fed a commercial total mixed ration in winter and grazing in summer. Across a $>6$-fold range in production variables, $R A$ content of milk ranged from 1 to $32 \mathrm{mg} / \mathrm{g}$ of fatty acids and desaturase index ranged from 0.03 to 0.15 . Days in milk, milk yield, milk fat content, and milk fat yield had minimal or no effect on RA content of milk fat or desaturase index $\left(R^{2}\right.$ values all $\left.<0.08\right)$. Thus, whereas nutrition and individual variation are major factors affecting RA content and desaturase index of milk fat, these values are minimally affected by days in milk, milk yield, milk fat content, and milk fat yield. Differences in these parameters do not need to be considered, therefore, when designing management strategies to increase RA content of milk fat.
\end{abstract}

(Key words: conjugated linoleic acid, milk fat, functional food, $\Delta^{9}$-desaturase)

Abbreviation key: CLA = conjugated linoleic acid, $\mathbf{R A}=$ rumenic acid.

Dairy products represent the primary source of conjugated linoleic acids (CLA) in the human diet, with cis-

Received March 7, 2005.

Accepted April 21, 2005.

Corresponding author: A. L. Lock; e-mail: all36@cornell.edu.

*Supported in part by MAFF postgraduate scholarship provided to A. L. Lock and DEFRA Grant LS3517. This research was also supported in part by the Cornell University Agricultural Experiment Station federal formula funds, Project No. NYC-127437, received from Cooperative State Research, Education and Extension Service, U.S. Department of Agriculture. Any opinions, findings, conclusions, or recommendations expressed in this publication are those of the authors and do not necessarily reflect the view of the U.S. Department of Agriculture

$\dagger$ Present address: Department of Animal Science, Cornell University, Ithaca, NY 14853.
9, trans-11 CLA (rumenic acid; RA) representing 75 to $90 \%$ of total CLA in dairy products (Parodi, 2003). Rumenic acid is principally produced by endogenous synthesis via the enzyme $\Delta^{9}$-desaturase with the precursor being vaccenic acid (trans-11 18:1), the predominant trans fatty acid produced in the rumen (Bauman et al., 2003). The potential benefits of RA on human health have led to widespread interest in increasing RA in the human diet, primarily through enhancing RA content of milk fat. The diet fed to cows is a major determinant of RA content of milk fat, with $>5$-fold increases in RA attainable by dietary formulations (Chilliard et al., 2001; Lock and Bauman, 2004). There is also a 2- to 3-fold range in RA content of milk fat among individual cows consuming the same diet (Bauman et al., 2003). Less reported are the effects of production variables, such as DIM, milk yield, and milk fat content and yield on RA content of milk fat. An understanding of the effects of production variables would be required for development of nutritional and management strategies aimed at production of RA-enriched dairy products.

The objective of the current analysis was to examine the main effects of production variables on RA content of milk fat and desaturase index. Variables examined were DIM, milk yield, and milk fat content and yield. A total of 430 milk samples were collected from 181 cows fed a commercial TMR in winter and grazing in summer; in each sampling month, 30 to 60 cows were selected at random for sampling. Details of the study design, sampling protocols, and analytical methods used in collection of these data were reported previously by Lock and Garnsworthy (2003). Because of the important contribution of endogenous synthesis to RA content of milk fat, we used a "desaturase index" as a proxy for $\Delta^{9}$-desaturase activity in the mammary gland, which has been shown to be correlated with $\Delta^{9}$-desaturase mRNA levels (Singh et al., 2004). This index has previously been defined as: [product of $\Delta^{9}$-desaturase]/ [product of $\Delta^{9}$-desaturase + substrate of $\Delta^{9}$-desaturase] (Malau-Aduli et al., 1997; Kelsey et al., 2003), and for the purposes of the current analysis, we used the 14:0 and cis-9 14:1 content of milk fat: [cis-9 14:1]/[cis-9 14:1 $+14: 0]$. 


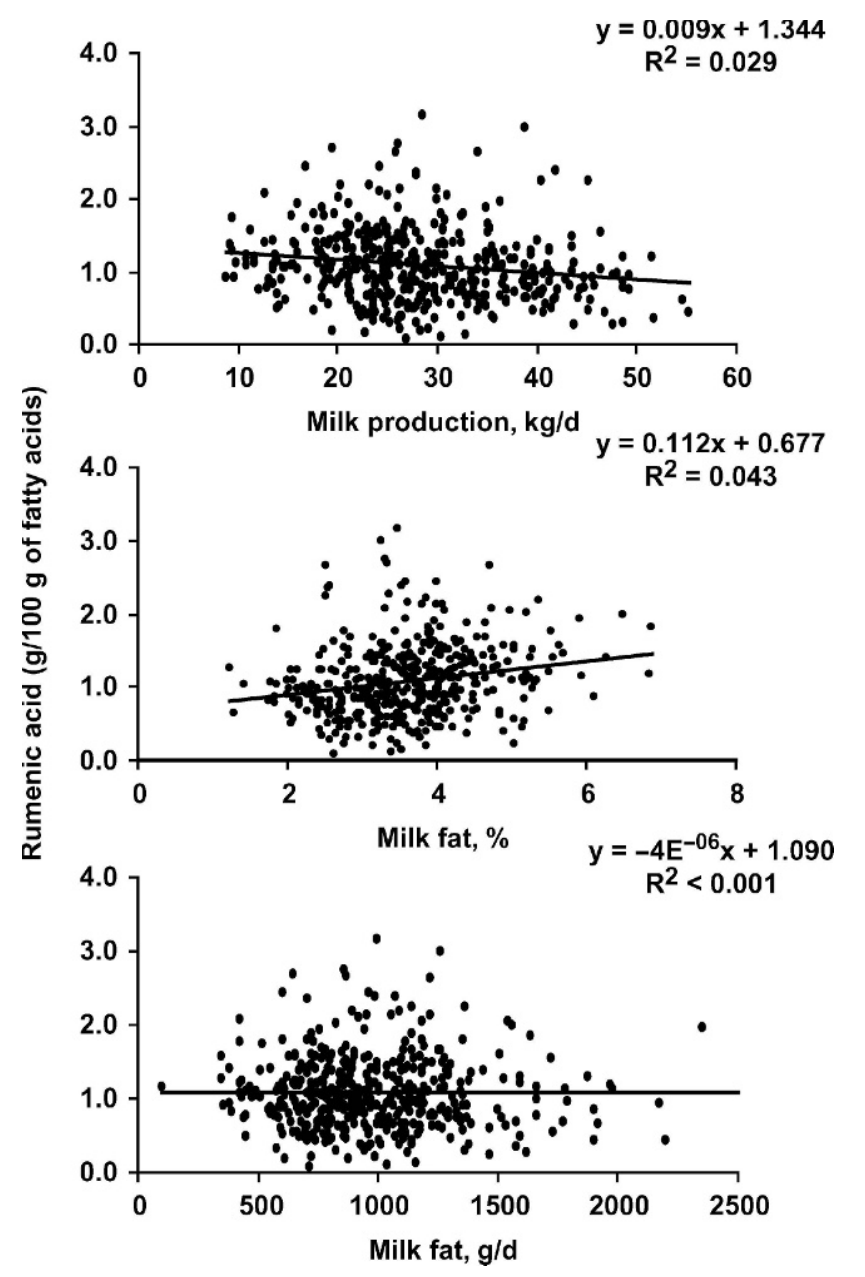

Figure 1. Variation in milk fat content of cis-9, trans-11 conjugated linoleic acid (rumenic acid) with milk yield (top panel), milk fat content (middle panel), and milk fat yield (bottom panel).

In the data set, stage of lactation ranged from 3 to 552 DIM, milk yield from 8.8 to $55.2 \mathrm{~kg} / \mathrm{d}$, milk fat content from 1.2 to $6.9 \%$, and milk fat yield from 347 to $2356 \mathrm{~g} / \mathrm{d}$. The RA content of milk ranged from 1 to $32 \mathrm{mg} / \mathrm{g}$ of fatty acids, and desaturase index from 0.03 to 0.15 . Data were analyzed by simple linear regression to examine the main effects of production variables because an initial screening showed that fixed effects of cows were not significant. The effects of diet on RA content of milk and desaturase index were reported in our previous publication (Lock and Garnsworthy, 2003). Milk yield, milk fat content and milk fat yield had little or no effect on RA content of milk ( $R^{2}$ values $<0.05$; Figure 1). Similarly, these variables did not affect desaturase index $\left(R^{2}\right.$ values $<0.03$; Figure 2$)$. Stage of lactation had little or no effect on RA content of milk or desaturase index $\left(R^{2}\right.$ values $<0.08$; Figure 3$)$.

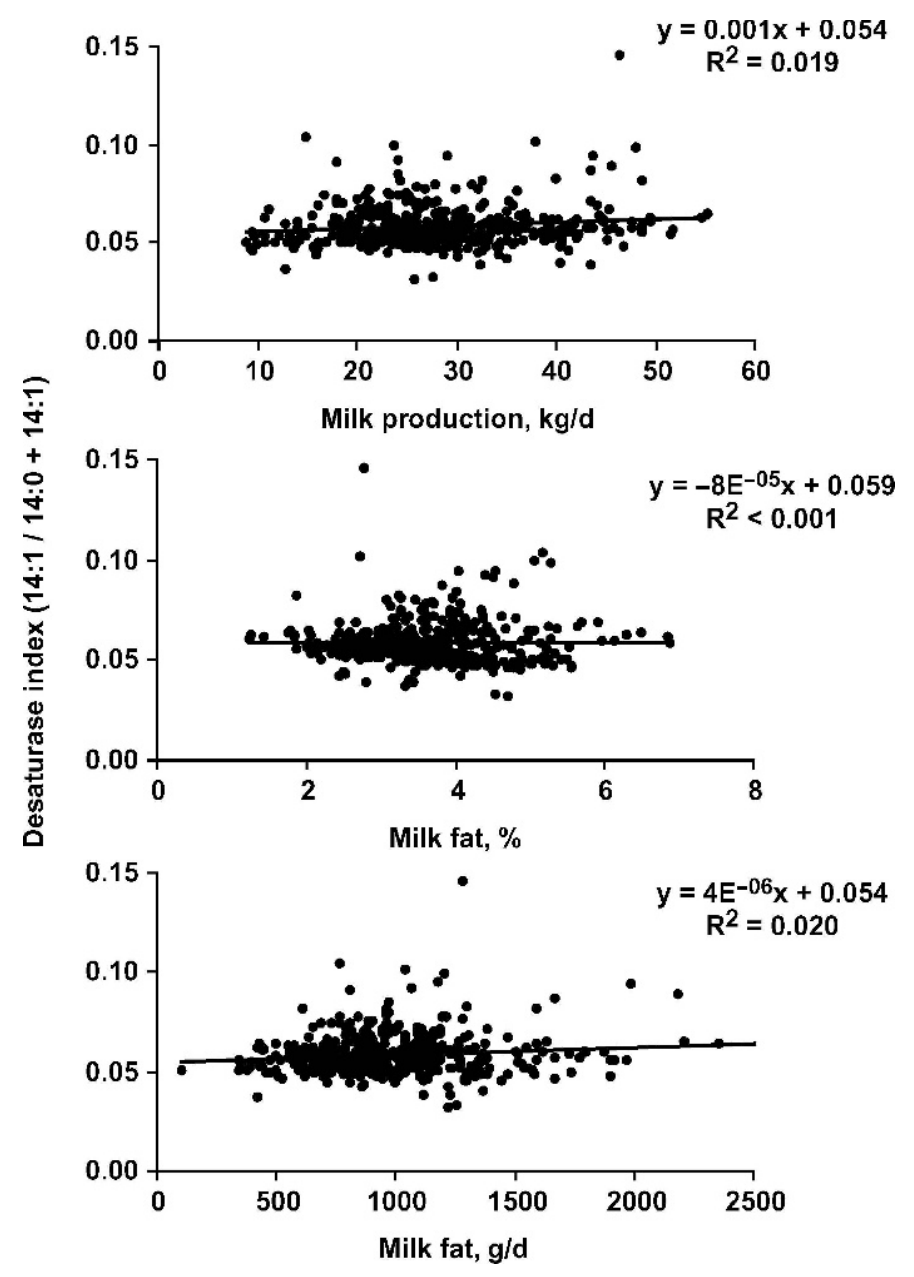

Figure 2. Variation in desaturase index with milk yield (top panel), milk fat content (middle panel), and milk fat yield (bottom panel). Desaturase index is based on the relationship between substrate and product for $\Delta^{9}$-desaturase and was calculated using 14:0 and cis-9 14:1 milk fatty acids.

The current study shows that, under normal conditions, RA content of milk and $\Delta^{9}$-desaturase activity in the mammary gland are independent of stage of lactation, milk yield, milk fat content, and milk fat yield. We previously reported that milk fat content significantly affected RA content of milk; however, this only accounted for $1.2 \%$ of the variation, whereas sampling month accounted for 57\% of the variation, which reflected changes in diet (Lock and Garnsworthy, 2003). Studies of this type are limited; the only other study, to our knowledge, investigating the same parameters was by Kelsey et al. (2003); in agreement with the current study, they observed that RA content and desaturase index of milk fat had little or no relationship to production parameters. Kelsey et al. (2003) sampled more than 200 cows consuming a common diet on the 

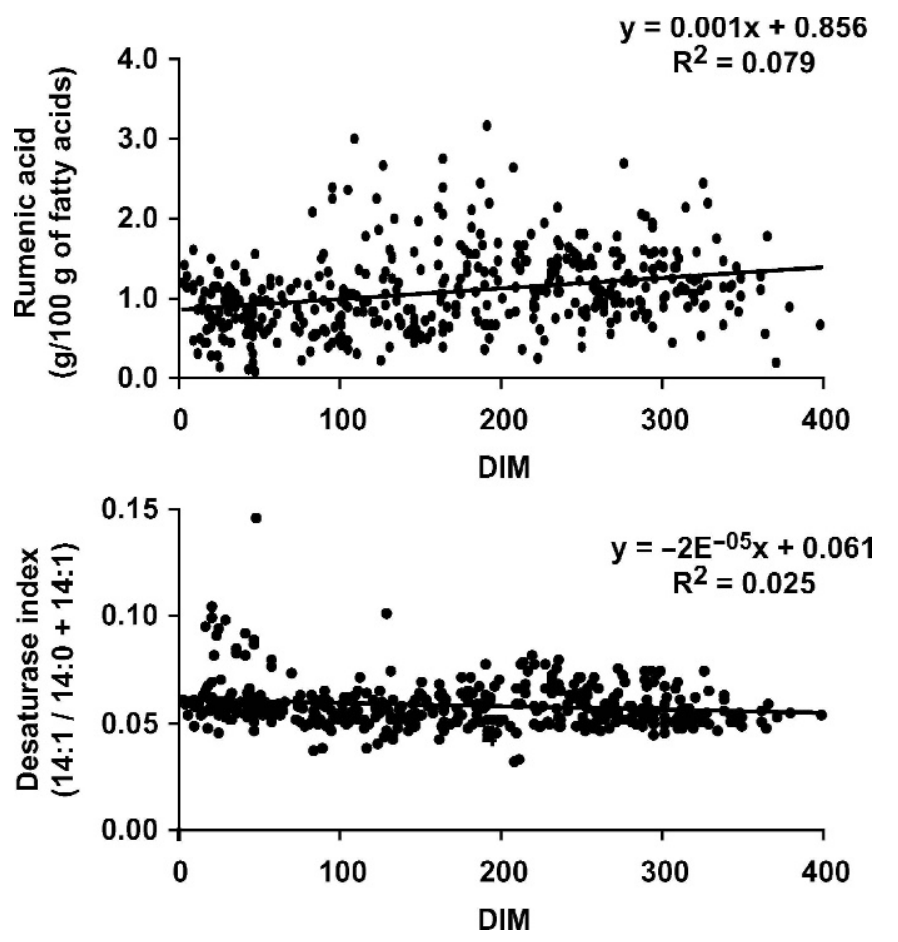

Figure 3. Variation in milk fat content of cis-9, trans-11 conjugated linoleic acid (rumenic acid; top panel) and desaturase index (bottom panel) with DIM. Data points represent milk samples from individual cows with the exception of 4 cows that were $>400$ DIM.

same day and observed a 3-fold variation among individuals in milk fat content of RA and desaturase index. Similar levels of variation have been reported in studies with fewer animals (Bauman et al., 2003). In addition, Lock and Garnsworthy (2002) and Peterson et al. (2002) demonstrated consistency in the ranking of individual cows for RA content of milk fat and desaturase index over time when cows were fed the same diet, and a consistency in ranking when cows were switched between diets. In the present study there was a greater degree of individual animal variation (Figures 1 and 2), which can be attributed to a combination of dietary differences over time and individual animal differences. Differences in RA content of milk among cows are most likely related to individual variation in rumen outflow of vaccenic acid and $\Delta^{9}$-desaturase activity in the mammary gland (Bauman et al., 2003).

Stage of lactation had little or no effect on RA content of milk or desaturase index. Although the effect of DIM was significant, it only accounted for $0.6 \%$ of the variation (Lock and Garnsworthy, 2003). These results are in agreement with those of Kelsey et al. (2003) who also observed a minimal effect of DIM, which accounted for $<2 \%$ of the total variation in RA content of milk fat.
Using fewer animals, Stanton et al. (1997) also reported no effect of DIM on RA content of milk. In contrast, Auldist et al. (1998) observed a significant increase in RA content of milk fat as pasture-fed cows went from early to late lactation, and Kay et al. (2004) reported a significant increase in the RA content of milk fat over the first $16 \mathrm{wk}$ of lactation in comparisons of genetic groups. However, changes in RA were small in these latter studies $(<3 \mathrm{mg} / \mathrm{g}$ of fatty acids) compared with the current study, with results from studies involving dietary comparisons (Chilliard et al., 2001; Lock and Bauman, 2004), and even investigations of the variation among individuals on the same diet (Bauman et al., 2003).

In summary, findings from the present analysis have important implications when considering the production of RA-enriched dairy products. Our knowledge of dietary effects is such that it is possible to significantly increase the RA content of milk fat. When considering commercial implementation of these dietary regimens, it is important to identify which animals to target. Clearly, under normal conditions, the RA content of milk and $\Delta^{9}$-desaturase activity in the mammary gland are independent of stage of lactation, milk yield, milk fat content, and milk fat yield. Therefore, differences in these parameters do not need to be taken into consideration when designing management strategies to increase RA; rather, it is more important to identify individual cows with the highest RA content in their milk fat.

\section{REFERENCES}

Auldist, M. J., B. J. Walsh, and N. A. Thomson. 1998. Seasonal and lactational influences on bovine milk composition in New Zealand. J. Dairy Res. 65:401-411.

Bauman, D. E., B. A. Corl, and D. G. Peterson. 2003. The biology of conjugated linoleic acids in ruminants. Pages 146-173 in Advances in Conjugated Linoleic Acid Research. Vol. 2. J.-L. Sébédio, W. W. Christie, and R. O. Adlof, ed. AOCS Press, Champaign, IL.

Chilliard, Y., A. Ferlay, and M. Doreau. 2001. Effect of different types of forages, animal fat or marine oils in cow's diet on milk fat secretion and composition, especially conjugated linoleic acid (CLA) and polyunsaturated fatty acids. Livest. Prod. Sci. 70:31-48.

Kay, J. K., W. J. Weber, H. Chester-Jones, L. Hansen, D. E. Bauman, B. A. Crooker, and L. H. Baumgard. 2004. Effects of genetic selection for milk yield and stage of lactation on milk fatty acid profiles. FASEB J. 18:A682. (Abstr.)

Kelsey, J. A., B. A. Corl, R. J. Collier, and D. E. Bauman. 2003. The effect of breed, parity, and stage of lactation on conjugated linoleic acid (CLA) in milk fat from dairy cows. J. Dairy Sci. 86:2588-2597.

Lock, A. L., and D. E. Bauman. 2004. Modifying milk fat composition of dairy cows to enhance fatty acids beneficial to human health. Lipids 39:1197-1206.

Lock, A. L., and P. C. Garnsworthy. 2002. Independent effects of dietary linoleic and linolenic fatty acids on the conjugated linoleic acid content of cows' milk. Anim. Sci. 74:163-176. 
Lock, A. L., and P. C. Garnsworthy. 2003. Seasonal variation in milk conjugated linoleic acid and $\Delta^{9}$-desaturase activity in dairy cows. Livest. Prod. Sci. 79:47-59.

Malau-Aduli, A. E. O., B. D. Siebert, C. D. K. Bottema, and W. S. Pitchford. 1997. A comparison of the fatty acid composition of triacylglycerols in adipose tissue from Limousin and Jersey cattle. Aust. J. Agric. Res. 48:715-722.

Parodi, P. W. 2003. Conjugated linoleic acid in food. Pages 101-122 in Advances in Conjugated Linoleic Acid Research. Vol. 2. J.L. Sébédio, W. W. Christie, and R. O. Adlof, ed. AOCS Press, Champaign, IL.
Peterson, D. G., J. A. Kelsey, and D. E. Bauman. 2002. Analysis of variation in cis-9, trans-11 conjugated linoleic acid (CLA) in milk fat of dairy cows. J. Dairy Sci. 85:2164-2172.

Singh, K., D. G. Hartley, T. B. McFadden, and D. D. S. Mackenzie. 2004. Dietary fat regulates mammary stearoyl CoA desaturase expression and activity in lactating mice. J. Dairy Res. 71:1-6.

Stanton, C., F. Lawless, G. Kjellmer, D. Harrington, R. Devery, J. F. Connolly, and J. Murphy. 1997. Dietary influences on bovine milk cis-9, trans-11 conjugated linoleic acid content. J. Food Sci. 62:1083-1086. 